\title{
Laurent Guyénot, La mort féerique. Anthropologie du merveilleux $\mathrm{XII}^{e}-\mathrm{XV}^{e}$ siècle
}

\section{G. Matteo Roccati}

\section{(2) OpenEdition}

\section{Journals}

\section{Édition électronique}

URL : http://journals.openedition.org/studifrancesi/1066

DOI : 10.4000/studifrancesi. 1066

ISSN : 2427-5856

\section{Éditeur}

Rosenberg \& Sellier

\section{Édition imprimée}

Date de publication : 1 novembre 2014

Pagination : 564

ISSN : 0039-2944

\section{Référence électronique}

G. Matteo Roccati, "Laurent Guyénot, La mort féerique. Anthropologie du merveilleux $x{ }^{e}{ }^{e}-x v^{\circledR}$ siècle ", Studi Francesi [En ligne], 174 (LVIII | III) | 2014, mis en ligne le 01 novembre 2014, consulté le 18 septembre 2020. URL : http://journals.openedition.org/studifrancesi/1066 ; DOI : https://doi.org/10.4000/ studifrancesi. 1066

Ce document a été généré automatiquement le 18 septembre 2020.

\section{(c)}

Studi Francesi è distribuita con Licenza Creative Commons Attribuzione - Non commerciale - Non opere derivate 4.0 Internazionale. 


\title{
Laurent Guyénot, La mort féerique. Anthropologie du merveilleux XII ${ }^{e}-\mathrm{XV}^{e}$ siècle
}

\author{
G. Matteo Roccati
}

\section{RÉFÉRENCE}

Laurent GUYÉNOT, La mort féerique. Anthropologie du merveilleux XII ${ }^{\mathrm{e}} \mathrm{XV}$ siècle, [Paris],

Gallimard, 2011 («Bibliothèque des histoires»), pp. 406.

1 Depuis longtemps la féerie dans la «matière de Bretagne» (au sens précisé p. 15) a été reconnue comme une marque de l'autre monde d'origine celtique, c'est-à-dire du monde des morts. L'ambition de cet ouvrage (qui reprend l'approche d'un livre précédent, voir Rassegna, LVI, 168, pp. 541-542), est d'expliciter la cohérence de l'imaginaire de la mort tel qu'il est véhiculé par les textes littéraires, saisis comme expression de la culture vernaculaire orale laïque, une culture «empreinte de conceptions religieuses peut-être marginales, mais qui avaient encore leur place dans une chrétienté très diverse, où les marges de l'orthodoxie étaient considérables» ( $\mathrm{p}$. 14).

2 Au-delà d'une curieuse attitude polémique - il suffit de se reporter aux nombreux auteurs cités pour constater, si besoin en était, que l'approche romantique du monde celte appartient au passé; il est difficile en même temps de nier les racines celtiques de l'imaginaire en question (cf. p. 14, 18) et la référence à Dumézil mériterait d'être approfondie -, le livre est riche d'exemples d'origines diverses, les lais et romans français et anglais constituant le corpus de référence privilégié. Il s'organise autour du constat que «[l]es idées laïques sur la mort se concentrent autour de deux pôles thématiques» (p. 20): la mort hérö̈que («récompensée par le Paradis; derrière certains lais se devine une vaste tradition orale où brillent les derniers feux d'un antique légendaire héroïque que l'aristocratie chérit avec nostalgie et qu'elle tente de préserver 
en le renouvelant», ibidem) et la mauvaise mort des âmes errantes («qui aspirent à leur apaisement, qui par la vengeance contre leur meurtrier, qui par l'amour fidèle d'un mortel», ibid.); l'élaboration légendaire se faisant par héroïsation, en niant la mort, et par projection retrospective sur l'origine surnaturelle du héros. Les différents chapitres passent en revue les textes qui traitent de ces thèmes en les regroupant en fonction de leur intérêt (je mentionne seulement quelques œuvres parmi les plus connues, à titre de repère): héroïsation, sainteté, royauté (I-III: Mort du roi Arthur, Guingamor), géniteurs surnaturels (IV: Merlin, Tydorel, Chevalier au Cygne), noces funèbres ou heroïsation nuptiale (V: Graelent, Lanval, Partonopeu de Blois), conquête de l'autre monde (VI-VIII: Yvain, Lancelot), morts errants (IX: Perceval, Wigalois), la morte amoureuse (X-XII: Guigemar, Mélusine). La Bibliographie des sources primaires et l'Index des oeuvres et auteurs cités complètent le volume. 